\title{
Viscosities of Copolyphosphates in Salt-Free Aqueous Solutions and Theta Solvents I.
}

\author{
H. N. Bhargava, ${ }^{*}$ Rita Rani SRIVAStava, and Manju SingH \\ Department of Chemistry, Gorakhpur University, Gorakhpur 273009, India
}

(Received May 7, 1987)

\begin{abstract}
The results of viscosity measurements on several samples of lithium-potassium copolyphosphates ( $\mathrm{Li}: \mathrm{K}$ ratio ranging from $9: 1$ to $5: 5$ ) in salt-free aqueous solutions and in theta solvents are reported. Molecular weights determined by end-group titration ranged from 400010000. In aqueous solutions the Fuoss equation parameter $A$ was found to be nearly proportional to the square of molecular weights, indicating rod-like structures of the poly-ions at infinite dilution. The concentrations of $\mathrm{NaBr}$ solutions acting as theta solvents at $35^{\circ} \mathrm{C}$ were determined for all cases and the viscosity data in $\theta$-solvents were utilized in calculating unperturbed dimensions which were found to lie in the range $4.7 \times 10^{-7} \mathrm{~cm}$ to $7.4 \times 10^{-7} \mathrm{~cm}$.

KEY WORDS Lithium Potassium Copolyphosphates / Intrinsic Viscosity /

Molecular Weight / Theta Solvent / Unperturbed Dimensions /
\end{abstract}

Viscosity has played a major role in crystallizing our present views on polyelectrolyte shape dynamics. A review by Eisenberg and King $^{1}$ also emphasizes its importance in the study of ion-containing polymers. While a number of papers dealing with various aspects of the viscosity behaviour of solutions of longchain polyphosphates has appeared, none of them presents a detailed study on copolyphosphates, the counter-cation copolymers in which more than one kind of cations are attached to the polyphosphate backbone:<smiles>CCP(=O)([O-])OP(=O)([O-])OP(C)(=O)[O-]</smiles>

Very interesting results have recently been reported by Bhargava et $a l^{2}$ on the intrinsic viscosity molecular weight relationships obtained for sodium potassium and lithium potassium copolyphosphates. As pointed out by Eisenberg and King, ${ }^{1}$ viscosity measurements in $\theta$-solvents have been reported only for a few polyelectrolytes. Allen and Watts ${ }^{3}$ have pointed out that in amorphous polymers, chains display dimensions which are experimentally indistinguishable from the values obtained in $\theta$ solvents, i.e., unperturbed dimensions. The present study reporting viscosity behaviour of lithium potassium copolyphosphates in salt free solutions and $\theta$ solvents is, therefore, quite important.

\section{EXPERIMENTAL}

\section{Materials and Methods}

(i) Preparation of Lithium-Potassium Copolyphosphates (LiKPP). ${ }^{* 1}$ To prepare the LiKPP samples, a reaction mixture of lithium carbonate, potassium dihydrogen orthophosphate and diammonium hydrogen phosphate, required in different $\mathrm{Li}: \mathrm{K}$ molar ratios ranging from 9:1 to 5:5 was taken in a platinum dish and mixed well with a glass stirrer. A set

* To whom correspondence should be sent.

*1 The abbreviation LiKPP, will be used throughout this paper to describe compounds having lithium and potassium cations attached to the polyphosphate chain. 
of five to six samples with similar $\mathrm{Li}: \mathrm{K}$ ratios were prepared. In every case, the mixture was first heated gradually in an oven at a temperature of $150-200^{\circ} \mathrm{C}$, taking care that the material did not spurt out in the initial stages when frothing took place due to brisk evolution of ammonia, carbon dioxide and water vapour. After the frothing subsided the crucible was placed in a Gallenkamp Muffle Furnace, already heated to the desired temperature in the range $700-900^{\circ} \mathrm{C}$ for desired durations of time. The muffle furnace was capable of maintaining a temperature within $\pm 10^{\circ} \mathrm{C}$.

The chemical reaction leading to the formation of lithium potassium copolyphosphate can be represented as follows:

$$
\begin{aligned}
& x \mathrm{KH}_{2} \mathrm{PO}_{4}+\left(\frac{1-x}{2}\right) \mathrm{Li}_{2} \mathrm{CO}_{3} \\
&+(1-x)\left(\mathrm{NH}_{4}\right)_{2} \mathrm{HPO}_{4} \rightarrow \\
& 1 / n\left[\mathrm{~K}_{x} \mathrm{Li}_{(1-x)} \mathrm{PO}_{3}\right]_{n}+2(1-x) \mathrm{NH}_{3} \\
&+\left(\frac{3-x}{2}\right) \mathrm{H}_{2} \mathrm{O}+\left(\frac{1-x}{2}\right) \mathrm{CO}_{2}
\end{aligned}
$$

The products were all obtained in the form of clear molten liquids which, after heating for various durations of time, were chilled between two stainless steel plates in contact with ice-cold water. The temperature of the preparation and time during which the mixture was kept in the muffle furnace are given in Table I. In all cases, the glassy product obtained on quenching was dried in an oven at $100^{\circ} \mathrm{C}$, powdered, placed in a sample tube and stored in a desiccator.

(ii) Determination of End-Group Molecular Weights. The $\mathrm{pH}$ was measured in all titrations by a glass electrode and a calomel half cell (a model 335 digital Systronics $\mathrm{pH}$-meter with an accuracy of \pm 0.01 ). A carbonate free $0.1 \mathrm{~N}$ $\mathrm{NaOH}$ solution was used as a base. Titrations were carried out as quickly as possible to avoid contamination by atmospheric carbon dioxide. The solution was also stirred con- tinuously with a magnetic stirrer while adding alkali from a microburette.

The end-group molecular weights were determined by a method similar to that described by Greenfield and Clift. $^{4} \mathrm{~A}$ freshly prepared $2 \%$ solution of the copolyphosphate in conductivity water was taken. A $25 \mathrm{ml}$ aliquot was diluted to $100 \mathrm{ml}$ and the $\mathrm{pH}$ adjusted to about 3.0 by adding drop by drop $1 N$ hydrochloric acid. It was then titrated between $\mathrm{pH} 4.5$ and 9.5 with $0.1 N$ sodium hydroxide solution $\left(V_{1}\right)$.

A $10 \mathrm{ml}$ aliquot was hydrolyzed by boiling on a sand bath with $25 \mathrm{ml}$ of $3 \mathrm{~N}$ nitric acid for at least $30 \mathrm{~min}$. It was then partially neutralized to $\mathrm{pH} 2-3$ with approximately $3 \mathrm{~N}$ sodium hydroxide solution and finally titrated between $\mathrm{pH} 4.5$ and 9.5 with $0.1 N$ sodium hydroxide solution $\left(V_{2}\right)$.

The number average chain length $\vec{n}$ was calculated using the formula

$$
\bar{n}=\frac{5 V_{2}}{V_{1}}
$$

By multiplying this number average chain length by the formula weight of the LiKPP sample in question, the number-average molecular weight was obtained.

(iii) Determination of Viscosity. The viscosity was measured with the help of a TuanFuoss viscometer ${ }^{5}$ at a flow time of about $120 \mathrm{~s}$. All measurements were done at $35 \pm 0.05^{\circ} \mathrm{C}$ in a thermostat. Before taking any measurements, the solutions of lithiumpotassium copolyphosphates were kept for $24 \mathrm{~h}$ so as to attain stability. ${ }^{2,6,7}$

(iv) Determination of Theta $(\theta)$ Solvents. In a theta solvent, there is no interaction between the solute and solvent and the value of the exponent $a$ of the Mark-Houwink equation is equal to 0.5 . For polyelectrolytes, a salt solution at a particular concentration is a theta solvent for a particular temperature. In our experiments the temperature was kept at $35^{\circ} \mathrm{C}$. Intrinsic viscosities of samples belonging to each series were determined in sodium bromide solutions in the concentration range from 
Table I. Fuoss equation parameters

\begin{tabular}{|c|c|c|c|c|c|c|c|c|}
\hline $\begin{array}{c}\text { Sample } \\
\text { No. }\end{array}$ & $\begin{array}{l}\text { Molar } \\
\text { ratio } \\
\mathrm{Li}: \mathrm{K}\end{array}$ & $\frac{\begin{array}{c}\text { Temperature of } \\
\text { preparation }\end{array}}{{ }^{\circ} \mathrm{C} \pm 10^{\circ} \mathrm{C}}$ & $\begin{array}{l}\text { Duration of } \\
\text { heating } \\
\text { before } \\
\text { quenching/h }\end{array}$ & $\bar{M}_{n}$ & $A$ & $B / A$ & $B$ & {$[\log (A / B+1)]$} \\
\hline 1 & $9: 1$ & 700 & 3 & 4180 & 0.7438 & 6.0460 & 4.4970 & 0.2185 \\
\hline 2 & $9: 1$ & 700 & 6 & 6330 & 2.1547 & 3.2310 & 6.9619 & 0.4906 \\
\hline 3 & $9: 1$ & 800 & 3 & 6630 & 2.2144 & 3.0143 & 6.6759 & 0.5208 \\
\hline 4 & $9: 1$ & 800 & 6 & 6710 & 2.2391 & 2.9594 & 6.6265 & 0.5288 \\
\hline 5 & $9: 1$ & 900 & 3 & 6790 & 2.4462 & 2.9070 & 7.1110 & 0.5365 \\
\hline 6 & $9: 1$ & 900 & 6 & 9000 & 2.3182 & 1.6299 & 5.4082 & 0.7880 \\
\hline 7 & $8: 2$ & 700 & 3 & 4450 & 1.7256 & 4.7037 & 8.1167 & 0.3275 \\
\hline 8 & $8: 2$ & 700 & 6 & 4800 & 1.8636 & 4.2319 & 7.8866 & 0.3734 \\
\hline 9 & $8: 2$ & 800 & 3 & 6220 & 3.2704 & 2.9438 & 9.6273 & 0.5311 \\
\hline 10 & $8: 2$ & 800 & 6 & 6360 & 3.3784 & 2.3539 & 9.6416 & 0.5446 \\
\hline 11 & $8: 2$ & 900 & 3 & 6580 & 3.5002 & 2.7211 & 9.5244 & 0.5652 \\
\hline 12 & $8: 2$ & 900 & 6 & 8370 & 5.7650 & 1.9433 & 11.2029 & 0.7115 \\
\hline 13 & $7: 3$ & 700 & 3 & 4650 & 1.2106 & 4.3976 & 5.3237 & 0.3568 \\
\hline 14 & $7: 3$ & 700 & 6 & 5270 & 1.4962 & 3.7010 & 5.5374 & 0.4317 \\
\hline 15 & $7: 3$ & 800 & 3 & 6220 & 2.3283 & 2.9438 & 6.8540 & 0.5311 \\
\hline 16 & $7: 3$ & 800 & 6 & 9150 & 3.6751 & 1.7283 & 6.3517 & 0.7624 \\
\hline 17 & $7: 3$ & 900 & 3 & 9160 & 4.7281 & 1.7253 & 8.1575 & 0.7631 \\
\hline 18 & $7: 3$ & 900 & 6 & 9550 & 5.4585 & 1.6292 & 8.8930 & 0.7880 \\
\hline 19 & $6: 4$ & 700 & 3 & 4650 & 1.7123 & 4.5872 & 7.8546 & 0.3385 \\
\hline 20 & $6: 4$ & 700 & 6 & 4890 & 1.8519 & 4.2808 & 7.9277 & 0.3684 \\
\hline 21 & $6: 4$ & 800 & 3 & 4960 & 1.9072 & 4.1981 & 8.0067 & 0.3769 \\
\hline 22 & $6: 4$ & 800 & 6 & 8090 & 4.7852 & 2.1478 & 10.2775 & 0.6680 \\
\hline 23 & $6: 4$ & 900 & 3 & 8630 & 5.4025 & 1.9798 & 10.6959 & 0.7003 \\
\hline 24 & $5: 5$ & 700 & 3 & 5190 & 1.6669 & 4.0783 & 6.7981 & 0.3895 \\
\hline 25 & $5: 5$ & 700 & 6 & 5560 & 1.7241 & 3.7189 & 6.4117 & 0.4296 \\
\hline 26 & $5: 5$ & 800 & 3 & 6350 & 2.0012 & 3.1124 & 6.2285 & 0.5069 \\
\hline 27 & $5: 5$ & 800 & 6 & 7590 & 3.1212 & 2.4510 & 7.6519 & 0.6106 \\
\hline 28 & $5: 5$ & 900 & 3 & 7790 & 4.3630 & 4.3669 & 10.3266 & 0.6258 \\
\hline 29 & $5: 5$ & 900 & 6 & 9550 & 5.0302 & 1.8015 & 9.0618 & 0.7444 \\
\hline
\end{tabular}

$0.05 \mathrm{M}$ to $0.50 \mathrm{M}$. After obtaining the value of $a$ in each case, plots of $a v s$. concentrations of $\mathrm{NaBr}$ were drawn and the concentration of $\mathrm{NaBr}$ at which $a=0.5$ was noted. This gave a $\theta$ solvent for $35^{\circ} \mathrm{C}$.

\section{RESULTS AND DISCUSSION}

\section{(a) Viscosities in Aqueous Solutions}

The values of reduced viscosity $\left(\eta_{\mathrm{sp}} / c\right)$ were obtained in conductivity water for all the samples of LiKPP having number-average molecular weights ranging from 4000-10000. Typical $\eta_{\mathrm{sp}} / c$ vs. $c$ curves for some of the samples of LiKPP are given in Figure 1.

All polyelectrolytes including polyphosphates give such curves. According to Fuoss, ${ }^{8}$ reduced viscosity in salt-free solutions is related to concentration in the following manner

$$
\frac{\eta_{\mathrm{sp}}}{c}=\frac{A}{1+B c^{1 / 2}}
$$

A plot of $c / \eta_{\mathrm{sp}} v s . c^{1 / 2}$ gives a straight line with slope $=B / A$ and intercept $=1 / A$ (recipro- 


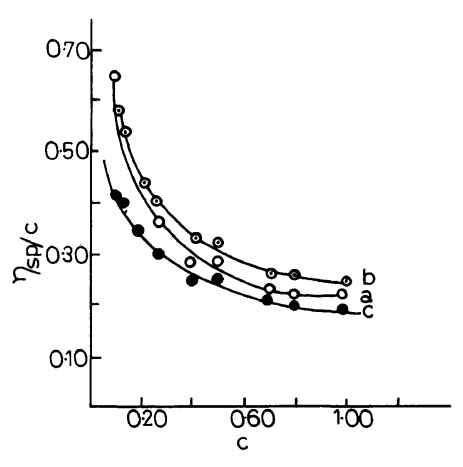

Figure 1. Relations between $\eta_{\mathrm{sp}} / c$ and $c$ for LiKPP samples: $\bigcirc=$ (a) $\mathrm{Li}: \mathrm{K}=9: 1$, sample No. $1 ; \odot=$ (b) $\mathrm{Li}: \mathrm{K}=8: 2$, sample No. 7; $=$ (c) $\mathrm{Li}: \mathrm{K}=7: 3$, sample No. 13.

cal of intrinsic viscosity in water).

A typical curve of $c / \eta_{\mathrm{sp}}$ against $c^{1 / 2}$ for one of the samples of LiKPP in salt-free solution is given in Figure 2. The values of $c / \eta_{\mathrm{sp}}$ and $c^{1 / 2}$ were used to obtain Fuoss equation parameters, $A, A / B$ and $B$ (Table I). Figure 3 shows the dependence of Fuoss equation parameters on molecular weight in the case of LiKPP samples ( $\mathrm{Li}: \mathrm{K}=9: 1)$. Similar plots were obtained in other cases also.

On the basis of $\log [\eta]-\log M$ plots it is possible to calculate the values of $K$ and $a$ for the Mark-Houwink relationship

$$
[\eta]=K M^{a}
$$

which can be written as

$$
\log [\eta]=\log K+a \log M
$$

Putting $[\eta]=A$ for salt-free solutions

$$
\log A=\log K+a \log M
$$

The best straight line curves consistent with the precision of the experimental points give values of $a$ ranging from 1.84 to 2.02 (Table II). These values are close to the theoretical slope expected for stiff rod-like molecules. ${ }^{9}$ The polyphosphate chains become highly extended as the ionic strength of the added salt approaches zero. Van Wazer et al. ${ }^{10}$ reached similar conclusions on the basis of flow bire-

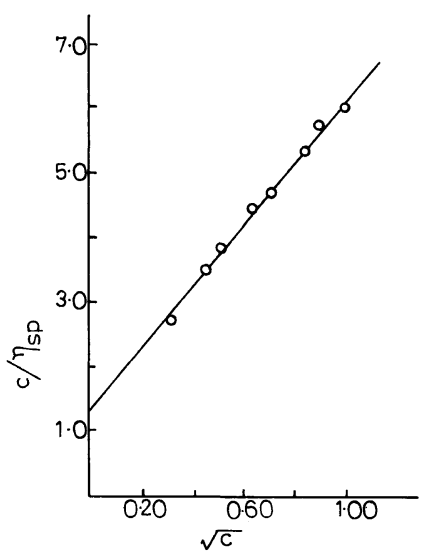

Figure 2. Relation between $c / \eta_{\text {sp }}$ and $\sqrt{c}$ for LiKPP sample ( $\mathrm{Li}: \mathrm{K}=9: 1$ ); sample No. 1 .

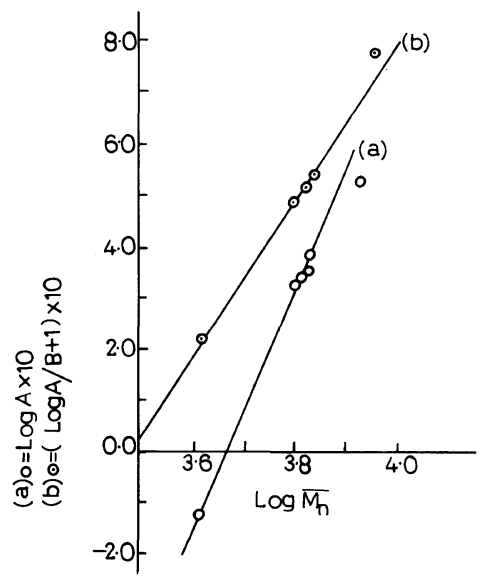

Figure 3. Dependence of Fuoss equation parameters on molecular weights in the case of LiKPP samples (Li : K=9:1); Table I.

fringence measurements.

The parameter $B$ in eq 2 depends on the dielectric constant of the medium. ${ }^{8}$ It also determines the degree to which the reduced viscosity is affected by concentration changes. While some authors report that this parameter is independent of molecular weight, ${ }^{11,12}$ this is not true in most cases. The values of $B$ reported in Table I are somewhat scattered. But they show an upward trend with increasing molecular weight. This scattering may be due to a fairly large experimental indeterminacy of parameter $A$ which actually is used in calculat- 
Table II. Dependence of Fuoss equation parameters on molecular weights in the case of LiKPP samples

\begin{tabular}{cccc}
\hline Ratio & $\begin{array}{c}\text { Relationships between } \\
A \text { and } \bar{M}_{n}\end{array}$ & $\begin{array}{c}\text { Relationships between } \\
A / B \text { and } \bar{M}_{n}\end{array}$ & $\begin{array}{c}\text { Relationships between } \\
B \text { and } \bar{M}_{n}\end{array}$ \\
\hline $9: 1$ & $A=0.40 \times 10^{-7} \bar{M}_{n}^{2.02}$ & $A / B=1.380 \times 10^{-7} \bar{M}_{n}^{1.68}$ & $B=0.293 \bar{M}_{n}^{0.19}$ \\
$8: 2$ & $A=1.28 \times 10^{-7} \bar{M}_{n}^{1.95}$ & $A / B=1.703 \times 10^{-6} \bar{M}_{n}^{1.40}$ & $B=0.075 \bar{M}_{n}^{0.56}$ \\
$7: 3$ & $A=1.17 \times 10^{-7} \bar{M}_{n}^{1.92}$ & $A / B=1.975 \times 10^{-6} \bar{M}_{n}^{1.38}$ & $B=0.092 \bar{M}_{n}^{0.54}$ \\
$6: 4$ & $A=2.25 \times 10^{-7} \bar{M}_{n}^{1.87}$ & $A / B=2.378 \times 10^{-6} \bar{M}_{n}^{1.34}$ & $B=0.099 \bar{M}_{n}^{0.52}$ \\
$5: 5$ & $A=2.45 \times 10^{-7} \bar{M}_{n}^{1.84}$ & $A / B=2.577 \times 10^{-6} \bar{M}_{n}^{1.34}$ & $B=0.096 \bar{M}_{n}^{0.50}$ \\
\hline
\end{tabular}

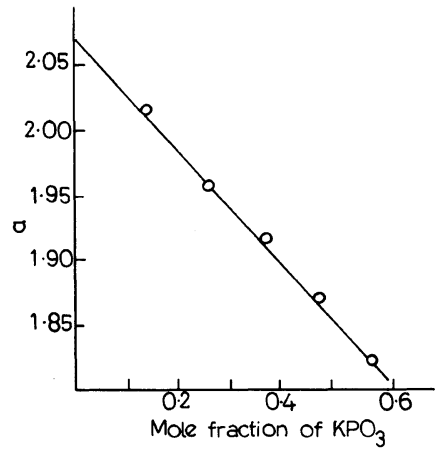

Figure 4. Plot of $a$ against mole fraction of $\mathrm{KPO}_{3}$ for LiKPP samples; Table II.

ing $B$. A typical plot showing dependence of parameters of Fuoss equation on molecular weight is given in Figure 3 for LiKPP samples with $\mathrm{Li}: \mathrm{K}$ ratio $9: 1$. Similar plots were obtained with other samples with different $\mathrm{Li}: \mathrm{K}$ ratios. All of them provided still stronger evidence for the molecular weight dependence of $B$. If $B$ were independent of the degree of polymerization, the two curves shown in Figure 3 whose ordinates represent $\log A$ and $\log (A / B)+1$, respectively, would be parallel, which they clearly are not. The equations obtained from such sets of curves are given in Table II.

The increase of $B$ with molecular weight is quite in line with our understanding of polyelectrolyte behaviour. While polyions are highly extended at infinite dilution, they tend to coil up more and more as the concentration, and with it the ionic strength, increase. As a consequence, the power of $M$ on which the reduced viscosity depends should decrease from about 2 at infinite dilution to about 1 when the concentration becomes very large.

A very interesting relationship is also observed when the values of $a$ are plotted againstthe mole fraction of $\mathrm{KPO}_{3}$ (Figure 4). A decrease in its value with increase in the mole fraction of $\mathrm{KPO}_{3}$ could mean that $a$ is also related to the degree of solvation of the polymer. A decrease in the value of $a$ indicates coiling up of the polymer chain due to decrease in solubility.

\section{(b) Unperturbed Dimensions}

The $\log [\eta]-\log \bar{M}_{n}$ plots in $\theta$ solvents were drawn and by the slopes of these plots the values of $a$ could be calculated as given in Table III. The theta solvent is the solution of $\mathrm{NaBr}$ at a concentration for which $a=0.5$. For its evaluation in every case, the values of $a$ were plotted against concentration of $\mathrm{NaBr}$. A typical plot is given in Figure 5. The values of $\theta$ solvent calculated from these plots are given in Table IV. The concentration of $\mathrm{NaBr}$ at which it acts as a $\theta$ solvent decreases from $0.58 \mathrm{~N}$ to $0.47 \mathrm{~N}$ as the mole fraction of $\mathrm{KPO}_{3}$ increases. Once again, this indicates that solubility decreases with increase in $\mathrm{KPO}_{3}$ units, and this is quite consistent with our expectations. The decrease in the value of $a$, the exponent of the Mark-Houwink relation with $0.035 N \mathrm{NaBr}$ as solvent, reported by Bhargava et al. $^{2}$ may now be seen in this light. Since $a$ is known to decrease with decrease in solubility ${ }^{13,14}$ the results obtained by 
Table III. Relevant data for determination of the $\theta$ solvent of lithium-potassium copolyphosphate

\begin{tabular}{|c|c|c|}
\hline $\begin{array}{l}\text { Ratio } \\
\text { Li : K }\end{array}$ & $\begin{array}{l}\text { Concentration } \\
\text { of } \mathrm{NaBr}\end{array}$ & $a$ \\
\hline $9: 1$ & 0.05 & 0.78 \\
\hline $9: 1$ & 0.10 & 0.76 \\
\hline $9: 1$ & 0.20 & 0.70 \\
\hline $9: 1$ & 0.35 & 0.59 \\
\hline $9: 1$ & 0.50 & 0.57 \\
\hline $8: 2$ & 0.05 & 1.01 \\
\hline $8: 2$ & 0.10 & 0.95 \\
\hline $8: 2$ & 0.20 & 0.80 \\
\hline $8: 2$ & 0.35 & 0.71 \\
\hline $8: 2$ & 0.50 & 0.56 \\
\hline $7: 3$ & 0.05 & 0.94 \\
\hline $7: 3$ & 0.10 & 0.84 \\
\hline $7: 3$ & 0.20 & 0.74 \\
\hline $7: 3$ & 0.35 & 0.64 \\
\hline $7: 3$ & 0.50 & 0.54 \\
\hline $6: 4$ & 0.05 & 0.90 \\
\hline $6: 4$ & 0.10 & 0.85 \\
\hline $6: 4$ & 0.20 & 0.74 \\
\hline $6: 4$ & 0.35 & 0.60 \\
\hline $6: 4$ & 0.50 & 0.52 \\
\hline $5: 5$ & 0.05 & 1.16 \\
\hline $5: 5$ & 0.10 & 1.12 \\
\hline $5: 5$ & 0.20 & 0.85 \\
\hline $5: 5$ & 0.35 & 0.65 \\
\hline $5: 5$ & 0.50 & 0.51 \\
\hline
\end{tabular}

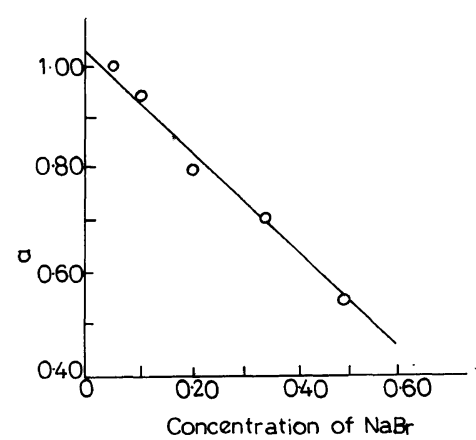

Figure 5. Plots of $a$ vs. concentration of $\mathrm{NaBr}$ for LiKPP samples (Li: $\mathrm{K}=8: 2)$; Table III.

Bhargava et al. $^{2}$ are in order.

The dependence of a $\theta$ solvent on the degree of solvation is illustrated by a plot of the
Table IV. Theta solvent data for samples of LiKPP

\begin{tabular}{cccc}
\hline $\begin{array}{c}\text { Serial } \\
\text { No. }\end{array}$ & $\begin{array}{c}\text { Ratio } \\
\mathrm{Li}: \mathrm{K}\end{array}$ & $\begin{array}{c}\text { Mole fraction } \\
\text { of } \mathrm{KPO}_{3}\end{array}$ & \begin{tabular}{c}
$\begin{array}{c}\theta \text {-Solvent } \\
\mathrm{NaBr}\end{array}$ \\
\cline { 3 - 3 }
\end{tabular} \\
\hline 1 & $9: 1$ & 0.1325 & 0.58 \\
2 & $8: 2$ & 0.2557 & 0.56 \\
3 & $7: 3$ & 0.3707 & 0.54 \\
4 & $6: 4$ & 0.4731 & 0.50 \\
5 & $5: 5$ & 0.5823 & 0.47 \\
\hline
\end{tabular}

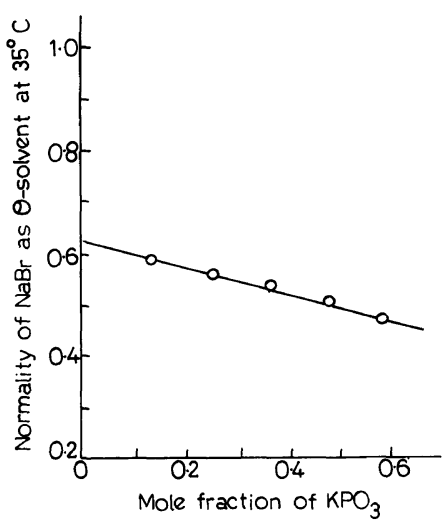

Figure 6. Plot of normality of $\mathrm{NaBr}$ as $\theta$-solvent at $35^{\circ} \mathrm{C}$ vs. mole fraction of $\mathrm{KPO}_{3}$ for LiKPP samples; Table IV.

concentration of $\mathrm{NaBr}$ (as $\theta$ solvent) vs. mole fraction of $\mathrm{KPO}_{3}$ in the copolyphosphate (Figure 6). A progressive decrease in the concentration of $\mathrm{NaBr}(\theta$-solvent $)$ with increase in $\mathrm{KPO}_{3}$ units is clearly observed. It is quite well known that potassium Kurrol salt is insoluble in water and dissolves only in presence of a salt. $^{6,15}$

To calculate the unperturbed dimensions $\left(r_{0}\right)$, the following well known equation ${ }^{16}$ was used:

$$
[\eta]_{\theta}=\phi\left(\frac{r_{0}^{2}}{M}\right)^{3 / 2} M^{1 / 2}=K M^{1 / 2}
$$

where $[\eta]_{\theta}$ is the intrinsic viscosity under theta conditions, $\phi$ is a "universal constant" often referred to as a Flory constant. According to Flory, its value should be close to $2 \times 10^{21}$, but workers in the polymer field have found it to 
Table V. Unperturbed dimension data for lithiumpotassium copolyphosphates

\begin{tabular}{|c|c|c|c|}
\hline $\begin{array}{c}\text { Sample } \\
\text { No. }\end{array}$ & $\begin{array}{c}\text { Theta solvent } \\
\mathrm{NaBr}\end{array}$ & {$[\eta]_{\theta}$} & $r_{0} \times 10^{-7}$ \\
\hline & $N$ & & \\
\hline 1 & 0.58 & 0.0688 & 5.1546 \\
\hline 2 & 0.58 & 0.0741 & 6.0673 \\
\hline 3 & 0.58 & 0.0804 & 6.3314 \\
\hline 4 & 0.58 & 0.0847 & 6.4684 \\
\hline 5 & 0.58 & 0.0900 & 6.6267 \\
\hline 6 & 0.58 & 0.0952 & 7.4165 \\
\hline 7 & 0.56 & 0.0635 & 5.1246 \\
\hline 8 & 0.56 & 0.0646 & 5.2856 \\
\hline 9 & 0.56 & 0.0656 & 5.8103 \\
\hline 10 & 0.56 & 0.0741 & 6.0771 \\
\hline 11 & 0.56 & 0.0836 & 6.3988 \\
\hline 12 & 0.56 & 0.0847 & 6.9630 \\
\hline 13 & 0.54 & 0.0519 & 4.8618 \\
\hline 14 & 0.54 & 0.0637 & 5.4275 \\
\hline 15 & 0.54 & 0.0646 & 5.7623 \\
\hline 16 & 0.54 & 0.0738 & 6.8517 \\
\hline 17 & 0.54 & 0.0772 & 6.9566 \\
\hline 18 & 0.54 & 0.0882 & 7.3824 \\
\hline 19 & 0.50 & 0.0479 & 4.7336 \\
\hline 20 & 0.50 & 0.0507 & 4.9056 \\
\hline 21 & 0.50 & 0.0535 & 5.0176 \\
\hline 22 & 0.50 & 0.0699 & 6.4387 \\
\hline 23 & 0.50 & 0.0744 & 6.7375 \\
\hline 24 & 0.47 & 0.0423 & 4.7108 \\
\hline 25 & 0.47 & 0.0439 & 4.8674 \\
\hline 26 & 0.47 & 0.0507 & 5.3518 \\
\hline 27 & 0.47 & 0.0659 & 6.1987 \\
\hline 28 & 0.47 & 0.0704 & 6.3914 \\
\hline 29 & 0.47 & 0.0732 & 6.9319 \\
\hline
\end{tabular}

lie in the range of $2 \times 10^{21}$ to $3 \times 10^{21}$. For some polyelectrolytes, a value close to $2.87 \times 10^{21}$ has been obtained ${ }^{17,18}$. Eisenberg and King $^{1}$ report a value of $2.6 \times 10^{21}$. Bhargava and Varma, ${ }^{19}$ on the basis of lightscattering experiments, have observed a value close to $2 \times 10^{21}$ for potassium polyphosphates. We have used a value of $2.1 \times 10^{21}$ predicted by Flory $^{16}$ for all kinds of high polymers.

The values of unperturbed dimensions ob- tained by eq 6 are given in Table V. It is interesting to note that the average unperturbed dimensions of these polyelectrolytes are quite close to those of non-ionic polymers of similar chain architecture, ${ }^{3}$ a fact borne out by modern theoretical approaches.

Acknowledgements. The authors are grateful to the University Grants Commission (UGC) and Council of Scientific and Industrial Research (CSIR) for financial assistance. RRS was a U.G.C. Junior Research Fellow and MS is a CSIR fellow. We are indebted to Dr. S. S. Das of the Department of Chemistry, Gorakhpur University for checking several mathematical calculations.

\section{REFERENCES}

1. A. Eisenberg and M. King, "Ion-Containing Polymers," Academic Press, New York, N. Y., 1977.

2. H. N. Bhargava, C. B. Sharma, and R. R. Srivastava, Polym. J., 18, 619 (1986).

3. G. Allen and D. C. Watts, "MTP International Review of Science," Physical Chemistry Series, Two, Vol. 2, A. D. Buckingham, Ed., Butterworth, London and Boston, 1975.

4. S. Greenfield and M. Clift, "Analytical Chemistry of the Condensed Phosphates," Pergamon Press, Oxford, New York, N. Y., 1975.

5. D. E. T. Tuan and R. M. Fuoss, J. Phys. Chem., 67, 1343 (1963).

6. J. R. Van Wazer, "Phosphorus and Its Compounds," Vol. 1, Interscience, New York, N. Y., 1958.

7. F. G. R. Gimblett, "Inorganic Polymer Chemistry," Butterworths, London, 1963.

8. A. Eisenberg and R. M. Fuoss, "Modern Aspects of Electrochemistry," J. O. M. Bockris, Ed., Academic Press, New York, N. Y., 1954, pp 1-46.

9. J. G. Kirkwood and P. L. Auer, J. Chem. Phys., 19, 281 (1951).

10. J. R. Van Wazer, M. Goldstein, and B. Farber, $J$. Am. Chem. Soc., 75, 1963 (1953).

11. R. M. Fuoss, J. Polym. Sci., 3, 603 (1948); Correction, ibid., 4, 96 (1949).

12. A. Oth and P. Doty, J. Phys. Chem., 56, 43 (1952).

13. C. Tanford, "Physical Chemistry of Macromolecules," John Wiley \& Sons, Inc., New York, London, 1961.

14. H. Morawetz, "Macromolecules in Solution," 2nd ed, Interscience Publisher, New York, N. Y., 1975.

15. B. K. Varma, Ph. D. Thesis, Entitled PhysicoChemical Studies on Long Chain Polyphosphates, 
Gorakhpur University, Gorakhpur, 1974.

16. P. J. Flory, "Principles of Polymer Chemistry," Cornell University Press, Ithaca, N. Y., 1953.

17. A. Takahashi and M. Nagasawa, J. Am. Chem. Soc., 86, 543 (1964).
18. A. Crescenzi, Adv. Polym. Sci., 5, 358 (1968).

19. H. N. Bhargava, P. K. Varma, and P. K. Agrawal, Colloid Polym. Sci., 256, 452 (1978). 